\title{
Difference between Internal and External Hydration of Hardened Cement Paste under Microwave Curing
}

\author{
Guoshun Yan, ${ }^{1}$ Jiazheng Li $\mathbb{D}^{2},{ }^{2}$ Yuqiang Lin, ${ }^{2}$ and Xia Chen $\mathbb{D}^{2}$ \\ ${ }^{1}$ Dagu Hydropower Branch of Huadian Tibet Energy Co. Ltd, Tibet 850099, China \\ ${ }^{2}$ Changjiang River Scientific Research Institute CWRC, Wuhan 430010, China \\ Correspondence should be addressed to Jiazheng Li; 1659959395@qq.com
}

Received 23 August 2021; Revised 26 September 2021; Accepted 8 October 2021; Published 31 October 2021

Academic Editor: Cristina Leonelli

Copyright (C) 2021 Guoshun Yan et al. This is an open access article distributed under the Creative Commons Attribution License, which permits unrestricted use, distribution, and reproduction in any medium, provided the original work is properly cited.

In order to investigate the difference between internal and external hydration of hardened cement paste under microwave curing, a comparative study on the hydration products, hydration degree, fracture morphology, and pore structure between the inner part and outer part of hardened cement paste $(\Phi 120 \mathrm{~mm} \times 120 \mathrm{~mm})$ under microwave curing was carried out by XRD-Rietveld refinement, TG-DSC, SEM, and MIP methods. The results show that the total hydration degree of the inner part is lower at early ages, but with the hydration, there is little difference in the hydration degree between inner and outer parts at later ages. Apart from granular AFt crystal formed in the inner part of hardened cement paste, there is little difference in the fracture morphology between internal and external hydration. The total porosity of the outer part is lower than that of the inner part.

\section{Introduction}

Microwave can accelerate the hydration of cement $[1,2]$ and supplementary cementitious materials [3] to improve the early age compressive strength $[4,5]$ with little damage to later-age strength and durability [6-8]. Therefore, much attention has been paid to the application of microwave curing for the precast concrete production [9-11] or rapid repair of cement-based materials [12]. Application of microwave curing also shows a broad perspective on the alkali activated materials $[13,14]$. With the development of society, economic and ecological needs have to be considered. Microwave process can shorten mold removal time significantly but also reduce the carbon emission by replacement of fossil fuels. Therefore, microwave curing is thought to be a promising method for rapid curing.

The principle of microwave heating for concrete is different from that of traditional steam heating. The concrete is dielectric composite material. Except the aggregate, all of the other components can absorb the microwave energy [4], which can be transferred to be heat energy according to equation (1). The heating performance is affected by the dielectric constants.

$$
\begin{aligned}
\frac{\Delta T}{\Delta t} & =\frac{P}{\rho C_{P}} \\
& =\frac{2 \pi f \varepsilon_{0} \varepsilon_{r}^{\prime \prime}|E|^{2}}{\rho C_{P}},
\end{aligned}
$$

where $\Delta T$ is the temperature difference of specimens; $\Delta t$ is the time for microwave radiation; $P$ is the microwave energy; $\rho$ is the density of the dielectric material; $C_{p}$ is the specific heat capacity; $f$ is the frequency of the electric field; $\varepsilon_{0}$ is the permittivity of vacuum; $\varepsilon_{r}^{\prime \prime}$ represents the imaginary part of complex permittivity; and $E$ is the electric field intensity.

However, the dielectric constants also affect the penetration depth of microwave through concrete according to the following equation:

$$
D_{p}=\frac{1}{\left(2 \pi f / v_{P}\right) \sqrt{\varepsilon_{r}^{\prime} \sqrt{(1+\tan \delta)^{2}}-1 / 2}}
$$

where $D_{p}$ is the penetration depth; $v_{p}$ is the propagation rate of microwave in dielectric materials; $\varepsilon_{r}^{\prime}$ is the real part of complex permittivity; and $\tan \delta$ is the loss tangent. 
When the microwave penetrates through concrete, volumetric heating will be formed, leading to a synchrony heating in the inner part and outer part of the concrete. Therefore, when compared with conventional heating, microwave curing shortens the heat conduction time. However, according to the research of Rattanadecho et al. [15], the penetration depth increases with the increase in temperature. For example, the penetration depth of microwave at $2.45 \mathrm{GHz}$ for type I Portland cement paste with water to cement ratio of 0.4 increases from $31 \mathrm{~mm}$ to $38 \mathrm{~mm}$ when the temperature increases from 30 to $90^{\circ} \mathrm{C}$. This is close to the thickness of reinforcement protective layer. In general, the thickness of plain concrete is also larger than $4 \mathrm{~cm}$ in practical application. Therefore, in order to investigate the difference between internal and external hydration of hardened cement paste under microwave curing, in this paper, a comparative study on the hydration products, hydration degree, fracture morphology, and pore structure between the inner part and outer part of hardened cement paste $(\Phi 120 \mathrm{~mm} \times 120 \mathrm{~mm})$ under microwave curing was carried out by XRD-Rietveld refinement, TG-DSC, SEM, and MIP methods.

\section{Materials and Methods}

2.1. Materials. Portland cement with 28 days compressive strength of $42.5 \mathrm{MPa}$ (China United Cement Corp., Beijing, China) was utilized for the current study, and deionized water was used for the mixing water. The density and specific area of the cement are $3150 \mathrm{~kg} / \mathrm{m}^{3}$ and $350 \mathrm{~m}^{2} / \mathrm{kg}$, respectively. Table 1 summarizes the chemical properties and mineral components of cement clinkers. Table 2 shows the chemical properties of cement. A cylindrical specimen $(\Phi 120 \mathrm{~mm} \times 120 \mathrm{~mm})$ is prepared for the study with the water/cement ratio of 0.50 .

2.2. Methods. The curing regimes under microwave heating are listed in Table 3. After 1 day, the specimens are cured in water with the ambient temperature of $20 \pm 2^{\circ} \mathrm{C}$.

A hydraulic machine is used to test the compressive strength. The loading rate is $2.4 \mathrm{kN} / \mathrm{s}$. The $\mathrm{X}$-ray diffraction (XRD) analysis is carried out by using a Rigaku D/max 2550 $\mathrm{X}$-ray diffractometer (Rigaku Corp., Japan) with $\mathrm{Cu} \mathrm{K} \alpha$ radiation generated at $40 \mathrm{kV}$ and $250 \mathrm{~mA}$. The scanning rate is $0.02^{\circ}$ step, and every step stays for 4 seconds. The specimen is pulverized into powder and then mixed with $20 \mathrm{wt} . \%$ $\alpha-\mathrm{Al}_{2} \mathrm{O}_{3}$ uniformly to refine by the Rietveld method with TOPAS. FEI QUANTA 200 is used for SEM-EDS tests. An AutoPore IV 9500 V1.09 Mercury Intrusion Pore Apparatus is used to calculate the pore sizes with penetration pressure from 1 to 29948 psi (pore size varies from less than $10 \mathrm{~nm}$ to $216800 \mathrm{~nm}$ ). The TG-DSC experiments are measured on the SDT Q600 analyzer of TA Company with approximately $20 \mathrm{mg}$ of sample under the dynamic $\mathrm{N}_{2}$ atmosphere. The heat for $\mathrm{CH}$ decomposition is used for the characterization of the $\mathrm{CH}$ content according to the DSC curves. Chemically bonded water $(H)$ of paste is calculated according to the TG test. The calculation method was as follows:

$$
H=\frac{w_{105^{\circ} \mathrm{C}}-w_{1000^{\circ} \mathrm{C}}}{w_{1000^{\circ} \mathrm{C}}}-\mathrm{LOI},
$$

where $w$ is the weight of samples at corresponding temperature and LOI is the loss on ignition of paste.

\section{Results and Discussion}

3.1. Compressive Strength. The specimen ML15 cured under microwave of $260 \mathrm{w}$ for 15 minutes is swelled as shown in Figure 1(a). The water evaporation and air expansion happen quickly because of the rapid temperature rising, leading to the expansion failure. The specimen cured with No. 2 curing regime is shown in Figure 1(b). Although the first radiation for 10 minutes is good for hardening, the expansion stress by the followed $15 \mathrm{~min}$ radiation is higher than the tensile strength of hardened cement paste. Therefore, the duration of microwave radiation cannot be too long at the early age. The specimens under the other curing regimes are shown in Figure 1(c). From Figure 1(c), it is seen that there are some air holes on the surface of the specimens, which may be attributed to insufficient vibration.

The compressive strength of hardened cement paste is listed in Table 3. Although the output energy is very high, the compressive strength of hardened cement paste cured by regimes of No. 3 and 4 is still relatively lower. This may be because of the excessive water loss caused by the continuous radiation, which is not conducive to the cement hydration. According to the compressive strength, the specimens cured by the regime of No. 7 were selected for the hydration and microstructure analysis. The sampling positions of inner part A and outer part B are as shown in Figure 2.

3.2. Hydration Products. The crystal structures of mineral phases are listed in Table 4. The XRD patterns and results of Rietveld refinement are as shown in Figure 3 and Table 5.

From Figure 3, we can see that the crystal phases of hydration products are calcium and katoite. As seen from Table 5, the hydration of $\mathrm{C}_{3} \mathrm{~S}$ in the inner part is a little lower than that in the outer part, but the trend is reversed for the hydration of $\mathrm{C}_{2} \mathrm{~S}$. The $\mathrm{Ca} / \mathrm{Si}$ ratio of $\mathrm{C}-\mathrm{S}-\mathrm{H}$ on average is about $1.7[23,24]$, that means, according to equations (4) and (5) [25], $1 \mathrm{~mol} \mathrm{C}_{3} \mathrm{~S}$ produces $1.5 \mathrm{~mol} \mathrm{CH}$, but $1 \mathrm{~mol} \mathrm{C}_{2} \mathrm{~S}$ only produces $1 \mathrm{~mol} \mathrm{CH}$. Therefore, more $\mathrm{CH}$ is produced in the outer part. Katoite is usually formed in the cement paste under elevated temperature curing. However, in this study, only slight difference in amount of katoite is observed between inner and outer part; therefore, it is hard to identify the effect of microwave curing on the formation of katoite. 
TABLE 1: Chemical and mineral components of cement clinkers (wt.\%).

\begin{tabular}{cccccccccccc}
\hline $\mathrm{SiO}_{2}$ & $\mathrm{Al}_{2} \mathrm{O}_{3}$ & $\mathrm{Fe}_{2} \mathrm{O}_{3}$ & $\mathrm{CaO}$ & $\mathrm{MgO}$ & $\mathrm{SO}_{3}$ & $\mathrm{Na}_{2} \mathrm{O}$ & $f-\mathrm{CaO}$ & $\mathrm{C}_{3} \mathrm{~S}$ & $\mathrm{C}_{2} \mathrm{~S}$ & $\mathrm{C}_{3} \mathrm{~A}$ & $\mathrm{C}_{4} \mathrm{AF}$ \\
\hline 21.90 & 4.81 & 3.41 & 65.15 & 1.95 & 0.51 & 0.65 & 0.95 & 56.32 & 20.29 & 6.98 & 10.37
\end{tabular}

TABle 2: Chemical components of cement (wt.\%).

\begin{tabular}{cccccccccc}
\hline $\mathrm{SiO}_{2}$ & $\mathrm{Al}_{2} \mathrm{O}_{3}$ & $\mathrm{Fe}_{2} \mathrm{O}_{3}$ & $\mathrm{CaO}$ & $\mathrm{MgO}$ & $\mathrm{SO}_{3}$ & $\mathrm{Na}_{2} \mathrm{O}$ & $f-\mathrm{CaO}$ & $\mathrm{CL}^{-}$ & $\mathrm{LOI}^{-}$ \\
\hline 20.81 & 4.92 & 3.41 & 62.65 & 2.38 & 2.65 & 0.67 & 0.81 & 0.012 & 2.01 \\
\hline
\end{tabular}

TABLE 3: The curing regime and compressive strength.

\begin{tabular}{|c|c|c|c|c|}
\hline \multirow{2}{*}{ No. } & \multirow{2}{*}{ Curing regime } & \multicolumn{3}{|c|}{ Compressive strength (MPa) } \\
\hline & & $6 \mathrm{~h}$ & $1 \mathrm{~d}$ & $120 \mathrm{~d}$ \\
\hline 1 & ML15 & Swelling & - & - \\
\hline 2 & ML10 + I30ML15 & Breaking & - & - \\
\hline 3 & ML10I30ML5 + I30ML5 + I30ML5 + I30ML20 & 12.4 & - & - \\
\hline 4 & ML10 + I30M5 + I30M5 + I30M5 + I30M25 & 10.0 & - & 19.6 \\
\hline 5 & ML5 + I30ML5 + I30ML5 + I30ML5 + I30M20 & 10.1 & - & - \\
\hline 6 & ML5 + I30ML5 + I30M5 + I30M5 + I30M20 & 12.7 & - & 28.2 \\
\hline 7 & $\mathrm{M} 5$ + I30M5 + I30M5 + I30M5 + I30M15 & 17.7 & 18.4 & 29.5 \\
\hline 8 & $\mathrm{M} 5+\mathrm{I} 30 \mathrm{M} 5+\mathrm{I} 30 \mathrm{M} 5+\mathrm{I} 30 \mathrm{M} 20$ & 16.3 & 21.4 & 33.2 \\
\hline
\end{tabular}

Note. ML and M represent the output power of $260 \mathrm{w}$ and $440 \mathrm{w}$, respectively, and I represents the interval time between two radiations, min. The followed Arabic numerals represent the time, min.
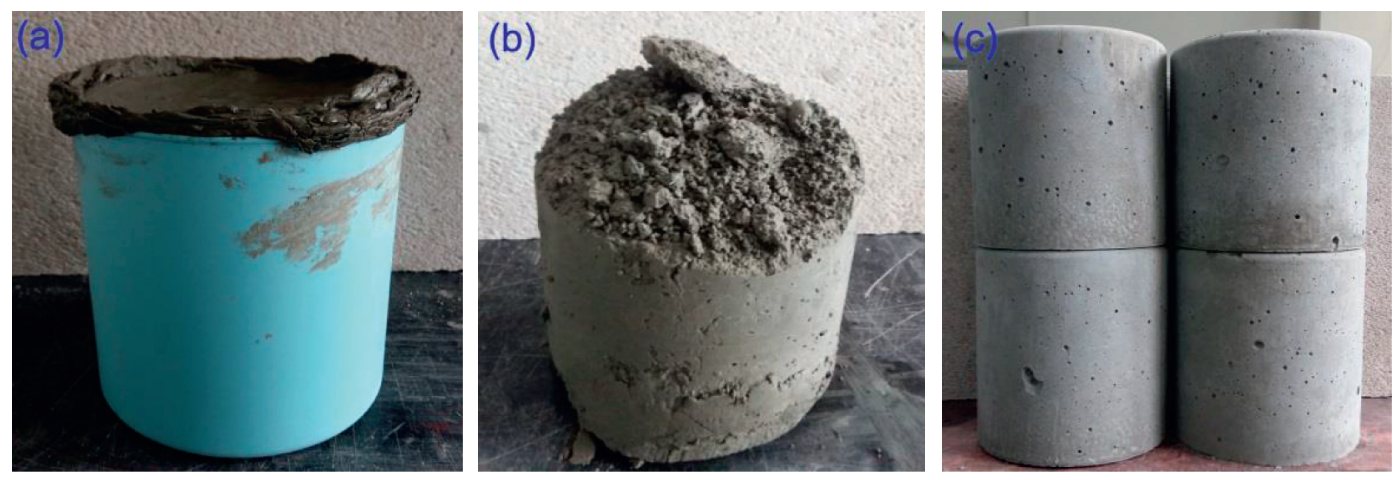

Figure 1: The specimens under microwave curing.

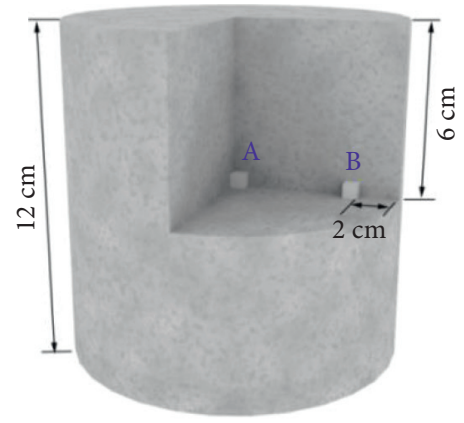

FIgURE 2: The sampling position for hydration and microstructure analysis.

$$
\begin{aligned}
& 3 \mathrm{CaO} \cdot \mathrm{SiO}_{2}+\mathrm{nH}_{2} \mathrm{O} \longrightarrow \mathrm{xCaO} \times \mathrm{SiO}_{2} \cdot \mathrm{yH}_{2} \mathrm{O}+(3-\mathrm{x}) \mathrm{Ca}(\mathrm{OH})_{2}, \\
& 2 \mathrm{CaO} \cdot \mathrm{SiO}_{2}+m \mathrm{H}_{2} \mathrm{O} \longrightarrow \mathrm{xCaO} \times \mathrm{SiO}_{2} \cdot \mathrm{yH}_{2} \mathrm{O}+(2-\mathrm{x}) \mathrm{Ca}(\mathrm{OH})_{2} .
\end{aligned}
$$


TABle 4: The crystal structure of phases used in Rietveld refinement.

\begin{tabular}{lcccccccc}
\hline Phase & Space group & $a(\AA)$ & $b(\AA)$ & $c(\AA)$ & $\alpha\left(^{\circ}\right)$ & $\beta\left(^{\circ}\right)$ & $\gamma\left(^{\circ}\right)$ & Reference \\
\hline $\mathrm{C}_{3} \mathrm{~S}$ & $\mathrm{C} 1 \mathrm{~m} 1$ & 33.1078 & 7.0355 & 18.5211 & 90 & 94.137 & 90 & {$[16]$} \\
$\mathrm{C}_{2} \mathrm{~S}$ & $\mathrm{P} 121 / \mathrm{n} 1$ & 5.48 & 6.76 & 9.28 & 90 & 85.45 & 90 & {$[17]$} \\
$\mathrm{C}_{4} \mathrm{AF}$ & $\mathrm{Ibm} 2$ & 5.584 & 14.6 & 5.374 & 90 & 90 & 90 & {$[18]$} \\
$\mathrm{C}_{3} \mathrm{~A}$ & $\mathrm{~Pa}-3$ & 15.263 & 15.263 & 15.263 & 90 & 90 & 90 & {$[19]$} \\
$\mathrm{CH}$ & $\mathrm{P}-3 \mathrm{~m} 1$ & 3.589 & 3.589 & 4.911 & 90 & 90 & 120 & {$[20]$} \\
$\mathrm{Katoite}$ & $\mathrm{Ia}-3 \mathrm{~d}$ & 12.5695 & 12.5695 & 12.5695 & 90 & 90 & 90 & {$[21]$} \\
$\mathrm{Al}_{2} \mathrm{O}_{3}$ & $\mathrm{R}-3 \mathrm{c}$ & 4.7606 & 4.7606 & 12.994 & 90 & 90 & 120 & {$[22]$} \\
\hline
\end{tabular}

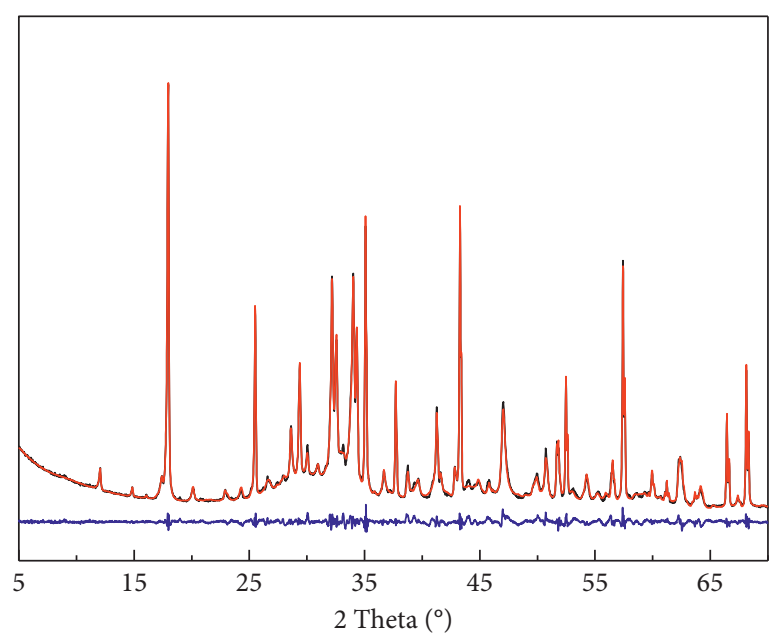

- Yobs
- Ycalc
- Diff.

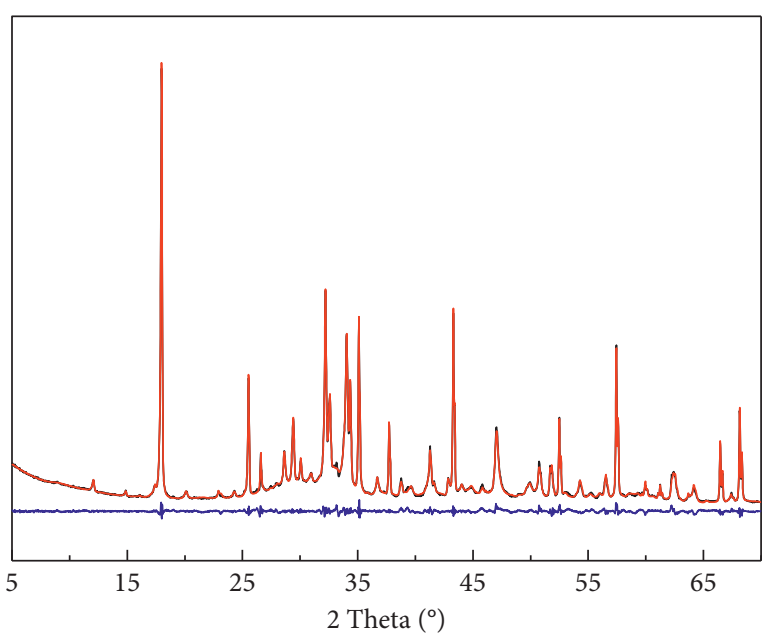

- Yobs
- Ycalc
- Diff.

(a)

(b)

FIGURE 3: The XRD-Rietveld refinement patterns: (a) inner part; (b) outer part.

TABLE 5: The results of XRD-Rietveld refinement.

\begin{tabular}{lcccccccccc}
\hline \multirow{2}{*}{ Sample } & \multicolumn{1}{c}{$\mathrm{C}_{3} \mathrm{~S}$} & $\mathrm{C}_{2} \mathrm{~S}$ & $\mathrm{C}_{3} \mathrm{~A}$ & $\mathrm{C}_{4} \mathrm{AF}$ & Katoite & $\mathrm{CH}$ & Amorphous & $\mathrm{Al}_{2} \mathrm{O}_{3}$ & $R_{\mathrm{p}}(\%)$ & $R_{\mathrm{wp}}(\%)$ \\
\hline Inner part & 21.3 & 12.6 & 3.5 & 1.6 & 2.6 & 7.8 & 30.6 & 20.0 & 3.28 \\
Outer part & 20.2 & 15.8 & 3.4 & 1.7 & 2.1 & 9.1 & 27.7 & 20.0 & 3.20 \\
\hline
\end{tabular}

3.3. Hydration Degree. The TG-DSC curves of specimens are shown in Figure 4. According to the calculation, the variation of chemically bonded water and calcium hydroxide is listed in Table 6. Because of the existence of amorphous $\mathrm{CH}$ [26-28], the quantitative analysis of $\mathrm{CH}$ is more accurate by DSC than XRD. Therefore, the $\mathrm{CH}$ content calculated by DSC results is used for the analysis of hydration degree. As seen from Table 6, the hydration degree of outer part is higher than that of inner part because of higher content of $\mathrm{CH}$ observed at 6 hours. From references $[1,2]$, microwave curing can reduce the surface tension of pore solution and increase the nucleation by increasing collision of molecules caused by the movement of molecules along with the electromagnetic field, accelerating the hydration of cement. As the penetration depth of microwave is smaller than $4 \mathrm{~cm}$, the microwave only affects the outer part of specimens; therefore, the hydration degree of outer part is higher. However, with the deepening of hydration of cement, the hydration degree of inner part and outer part grows close to each other. This may be attributed to the curing in water, which is conducive to the hydration of the anhydrous at later ages.

3.4. Fracture Morphology. The fracture morphology of hardened cement paste at the age of 6 hours is as shown in Figure 5. As seen from Figures 5(a) and 5(b), there are capillary pores both in the inner and outer parts. The products (IP) of hydration of cement particles both in the inner and outer parts of hardened cement paste present a flocculent structure as shown in Figures 5(c) and 5(d). However, there is a lot of granular crystal in the inner part as 


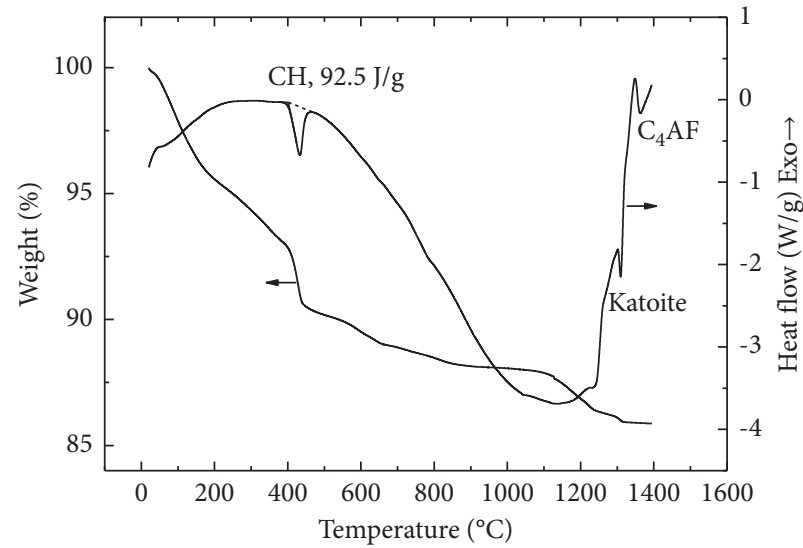

(a)

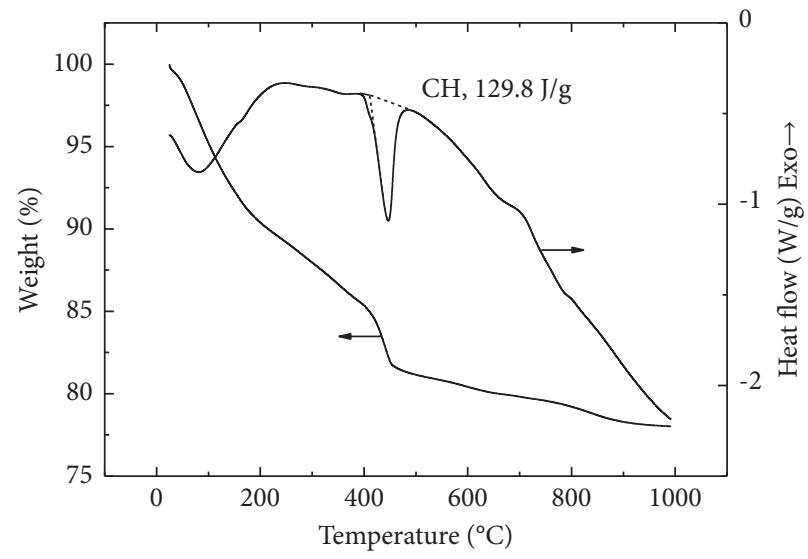

(c)

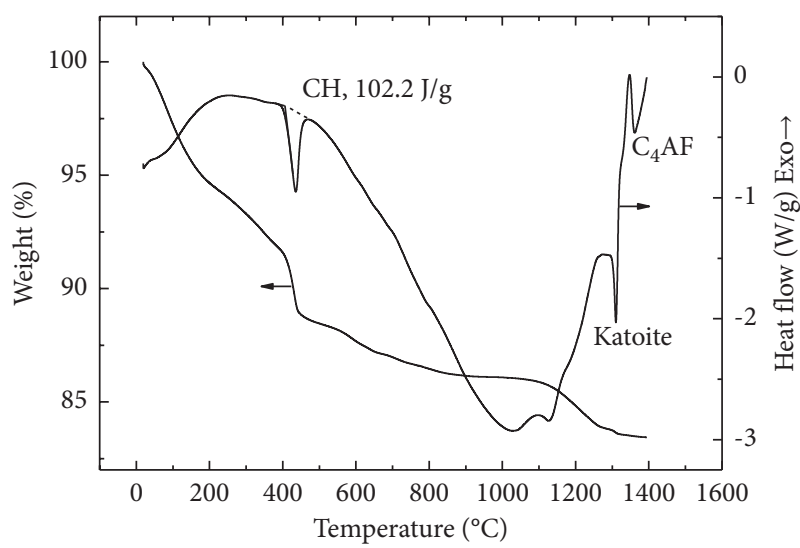

(b)

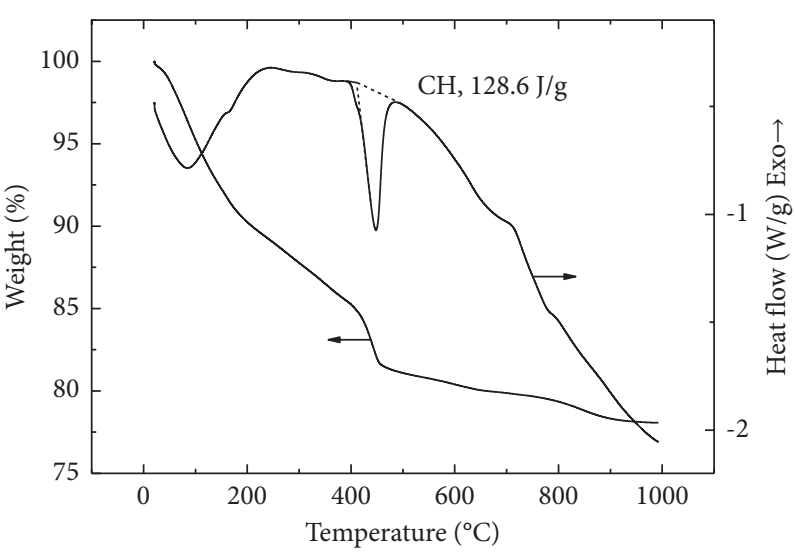

(d)

FiguRE 4: The TG-DSC curves of specimens: (a) inner part at 6 hours; (b) outer part at 6 hours; (c) inner part at 120 days; (d) outer part at 120 days.

TABLE 6: The content of chemically bonded water and calcium hydroxide.

\begin{tabular}{lcccc}
\hline & Inner part & \multicolumn{2}{c}{ Outer part } \\
& 6 hours & 120 days & 6 hours & 120 days \\
\hline Chemically bonded water (wt.\%) & 9.0 & 19.6 & 10.7 & 19.7 \\
Heat for CH decomposition $(\mathrm{J} / \mathrm{g})$ & 92.5 & 129.8 & 108.2 & 128.6 \\
\hline
\end{tabular}

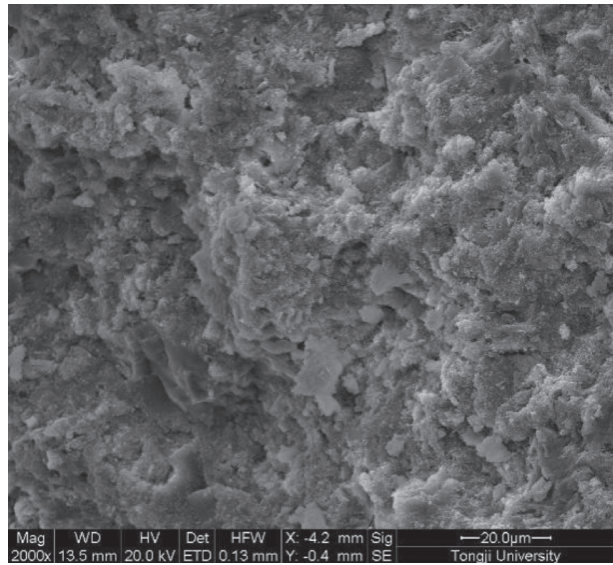

(a)

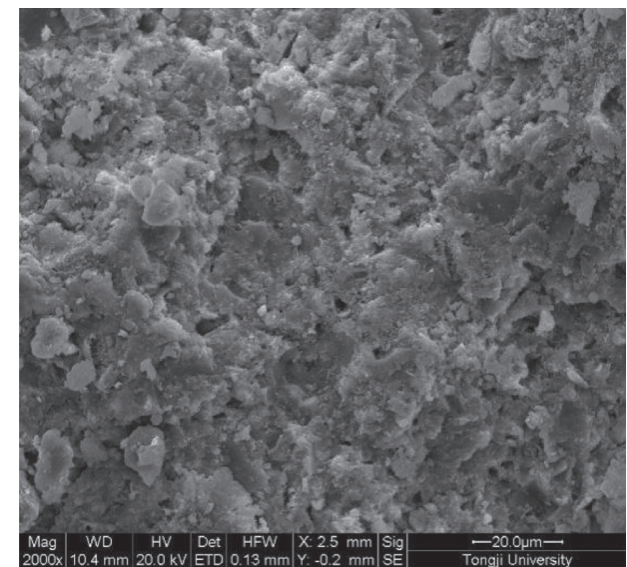

(b)

Figure 5: Continued. 


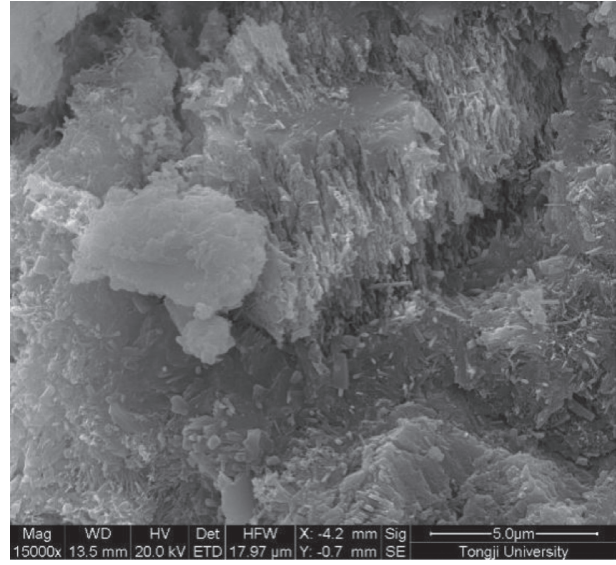

(c)

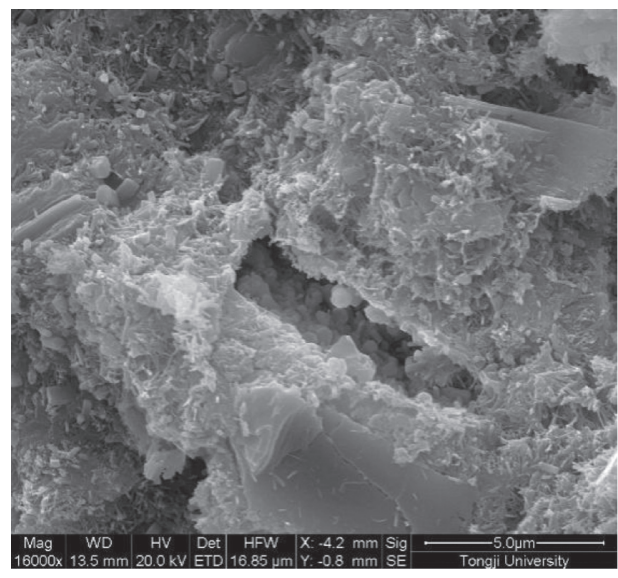

(e)

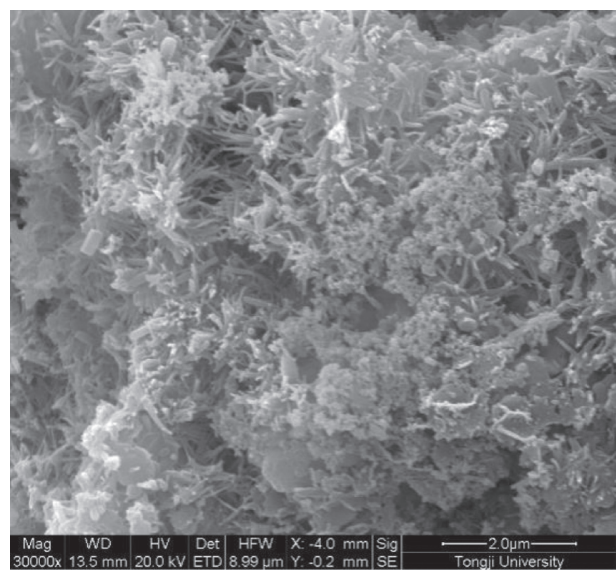

(g)

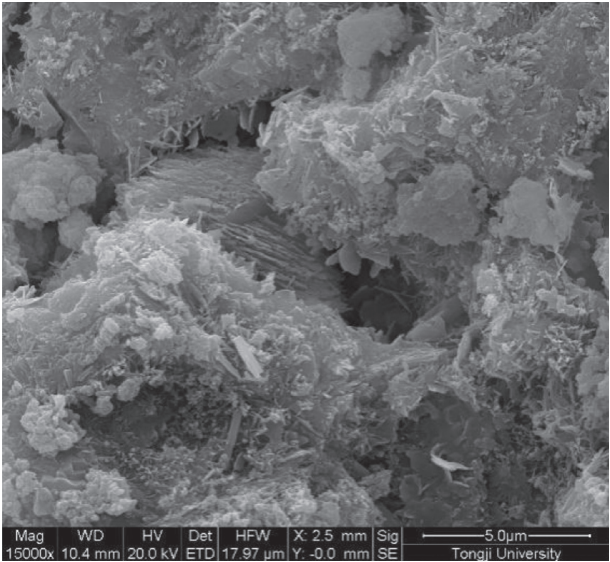

(d)

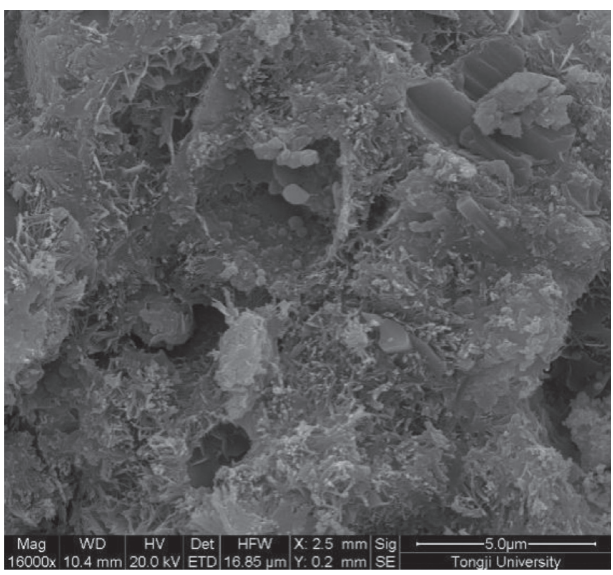

(f)

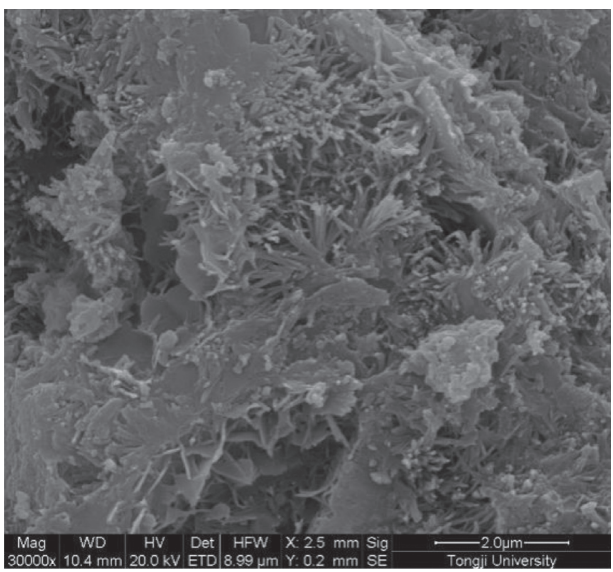

(h)

FiguRE 5: The fracture morphology of inner part and outer part of specimens: (a) inner part; (b) outer part; (c) inner part; (d) outer part; (e) inner part; (f) outer part; (g) inner part; (h) outer part.

demonstrated in Figure 5(c). This may be nano-sized ettringite (AFt). In addition, there is flaked AFm crystal as shown in Figures 5(e) and 5(f) and bunchy C-S-H as shown in Figures 5(g) and 5(h) formed both in the inner part and outer part.
3.5. Pore Structure. The pore size distribution of hardened cement paste is shown in Figure 6. From Figure 6(a), the most probable pore diameter of pastes in inner part at the age of 6 hours has two peaks around 0.03 and $0.07 \mu \mathrm{m}$, respectively, and the most probable pore diameter in outer 


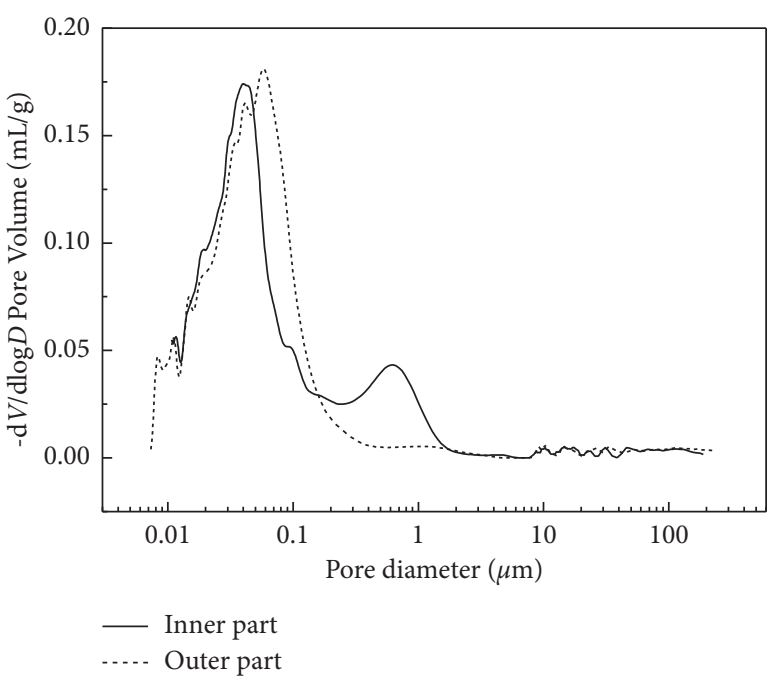

(a)

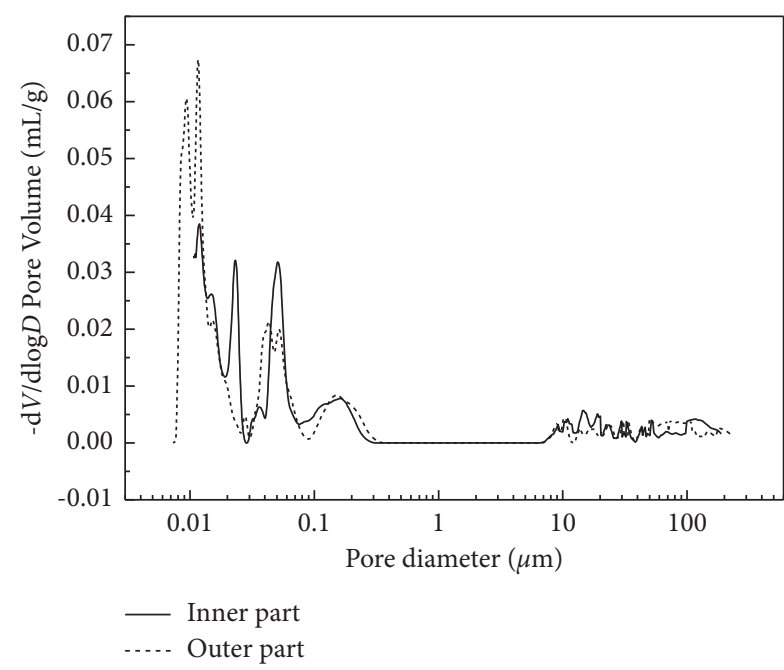

(b)

FIGURE 6: The pore size distribution curves of hardened cement paste: (a) 6 hours; (b) 120 days.

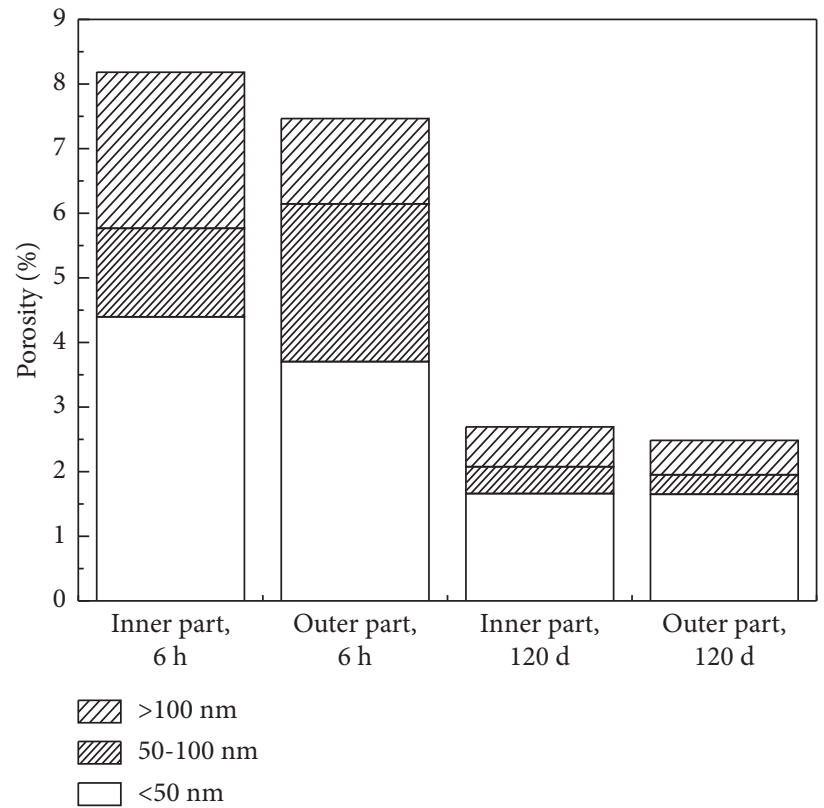

FIGURE 7: The porosity of hardened cement paste.

part has a peak around $0.05 \mu \mathrm{m}$. With the deepening of hydration, the most probable pore diameter is decreased. At the age of 120 days, the most probable pore of both the inner part and outer part has peaks around $0.2,0.06$, and $0.01 \mu \mathrm{m}$, and an another peak around $0.02 \mu \mathrm{m}$ is observed for the most probable pore of the inner part of hardened cement paste.

According to the research of Mehta [29], the pores in the hardened cement paste are divided into three groups: meso pores $(<50 \mathrm{~nm})$, middle capillary pores $(50-100 \mathrm{~nm})$, and large capillary pores $(>100 \mathrm{~nm})$. The pore diameter of pastes is grouped as shown in Figure 7. As seen from Figure 7, at the age of 6 hours, the total porosity in the outer part is lower than that in the inner part; the porosity of large capillary pores and meso pores is lower in the outer part, but the porosity of middle capillary pores is higher. With the deepening of hydration, the total porosity of inner and outer parts is gradually decreased. At the age of 120 days, the porosity in the outer part is still lower than that in the inner part. This is primarily attributed to the decrease in the porosity of capillary pores.

\section{Conclusions}

(1) The inner part is characterized by higher hydration degree of $\mathrm{C}_{2} \mathrm{~S}$ and lower hydration degree of $\mathrm{C}_{3} \mathrm{~S}$ than the outer part under microwave curing, yet the overall hydration degree of the inner part is lower at 
6 hours. With the deepening of hydration, there is little difference in the hydration degree between inner and outer parts at the age of 120 days.

(2) Apart from some granular AFt crystals formed in the inner part of hardened cement paste, there is little difference in the fracture morphology between internal and external hydration products.

(3) Under microwave curing, the total porosity of the outer part is lower than that of inner part. The porosity of large capillary pores and mesopores is decreased yet that of the middle capillary pores is increased in the outer part of hardened cement paste.

(4) With the deepening of hydration, the total porosity of hardened cement is still slightly lower in the outer part at the age of 120 days. This is attributed to the reduction of capillary pores.

\section{Data Availability}

The underlying data are included within the manuscript.

\section{Conflicts of Interest}

The authors declare that they have no conflicts of interest.

\section{Acknowledgments}

The authors would like to acknowledge full support of National Key R \& D Plan under grant no. 2019YFC1510803, NSFC under Grant Nos. 51979019, 51979011 and U2040222, and China Central Nonprofit Scientific Research Program under Grant Nos. CKSF2019374 and CKSF2021483.

\section{References}

[1] N. Makul, "Innovative hybrid curing method for accelerating the strength of high-performance cement paste using microwave heating coupling with low-pressure processing," Construction and Building Materials, vol. 105, pp. 245-252, 2016.

[2] Y. Kong, P. Wang, S. Liu, and Z. Gao, "Hydration and microstructure of cement-based materials under microwave curing," Construction and Building Materials, vol. 114, pp. 831-838, 2016.

[3] Y. Kong, P. Wang, S. Liu, Z. Gao, and M. Rao, "Effect of microwave curing on the hydration properties of cementbased material containing glass powder," Construction and Building Materials, vol. 158, pp. 563-573, 2018.

[4] R. G. Hutchison, J. T. Chang, H. M. Jennings, and M. E. Brodwin, "Thermal acceleration of Portland cement mortars with microwave energy," Cement and Concrete Research, vol. 21, no. 5, pp. 795-799, 1991.

[5] K. L. Chung, C. Song, Y. Li, and C. Zhang, "Correlation between microwave properties and compressive strength of engineered cementitious mortar," Microwave and Optical Technology Letters, vol. 58, no. 11, pp. 2696-2699, 2016.

[6] M.-G. Lee, "Preliminary study for strength and freeze-thaw durability of microwave- and steam-cured concrete," Journal of Materials in Civil Engineering, vol. 19, no. 11, pp. 972-976, 2007.
[7] M.-G. Lee, Y. Huang, and Y.-C. Kan, "The strength and rapid chloride permeability of microwave cured concrete," International Journal of Applied Science \& Engineering, vol. 5, no. 1, pp. 53-63, 2007.

[8] T. Pheeraphan and C. K. Y. Leung, "Freeze-thaw durability of microwave cured air-entrained concrete," Cement and Concrete Research, vol. 27, no. 3, pp. 427-435, 1997.

[9] N. Makul, P. Rattanadecho, and D. K. Agrawal, "Applications of microwave energy in cement and concrete - a review," Renewable and Sustainable Energy Reviews, vol. 37, no. 3, pp. 715-733, 2014.

[10] N. Makul, B. Chatveera, and P. Ratanadecho, "Use of microwave energy for accelerated curing of concrete: a review," Songklanakarin Journal of Science and Technology, vol. 31, no. 1, pp. 1-13, 2009.

[11] A. Buttress, A. Jones, and S. Kingman, "Microwave processing of cement and concrete materials - towards an industrial reality?" Cement and Concrete Research, vol. 68, pp. 112-123, 2015.

[12] P. Mangat, K. Grigoriadis, and S. Abubakri, "Microwave curing parameters of in-situ concrete repairs," Construction and Building Materials, vol. 112, pp. 856-866, 2014.

[13] B.-J. Kim, C. Yi, and K.-I. Kang, "Microwave curing of alkaliactivated binder using hwangtoh without calcination," Construction and Building Materials, vol. 98, pp. 465-475, 2015.

[14] S. Shi, Y. Bai, H. Li, D. Xu, and P. Basheer, "Comparative study of alkali-activated fly ash manufactured under pulsed microwave curing and thermal oven curing," in Proceedings of the the 4th Conference on the Durability of Concrete Structures, West Lafayette, IA, USA, 2014.

[15] P. Rattanadecho, N. Suwannapum, and W. Cha-um, "Interactions between electromagnetic and thermal fields in microwave heating of hardened type I-cement paste using a rectangular waveguide (influence of frequency and sample size)," Journal of Heat Transfer, vol. 131, no. 8, pp. 82-101, 2009.

[16] Á. G. De La Torre, S. Bruque, J. Campo, and M. A. G. Aranda, "The superstructure of C3S from synchrotron and neutron powder diffraction and its role in quantitative phase analyses," Cement and Concrete Research, vol. 32, no. 9, pp. 1347-1356, 2002.

[17] C. M. Midgley, "The crystal structure of $\beta$ dicalcium silicate," Acta Crystallographica, vol. 5, no. 3, pp. 307-312, 1952.

[18] A. A. Colville and S. Geller, "The crystal structure of brownmillerite, $\mathrm{Ca}_{2} \mathrm{FeAlO}_{5}$," Acta Crystallographica, vol. 27, no. 12, pp. 2311-2315, 2007.

[19] P. Mondal and J. W. Jeffery, "The crystal structure of tricalcium aluminate, Ca3Al2O6," Acta Crystallographica Section B Structural Crystallography and Crystal Chemistry, vol. 31, no. 3, pp. 689-697, 1975.

[20] L. Desgranges, D. Grebille, G. Calvarin, G. Chevrier, N. Floquet, and J.-C. Niepce, "Hydrogen thermal motion in calcium hydroxide: $\mathrm{Ca}(\mathrm{OH})_{2}$," Acta Crystallographica, vol. 49, no. 5, pp. 2231-2234, 2007.

[21] G. A. V. Dreele and B. Robert, "Neutron powder diffraction study of hydrogarnet to $9.0 \mathrm{GPa}$," American Mineralogist, vol. 81, no. 9-10, pp. 1097-1104, 1996.

[22] V. G. Tsirelson, R. G. Gerr, R. P. Ozerov, and Y. T. Struchkov, "Ruby structure peculiarities derived from X-ray diffraction data localization of chromium atoms and electron deformation density," Physica Status Solidi (A), vol. 87, no. 2, pp. 425-433, 1985.

[23] S. Liu, L. Wang, Q. Li, and J. Song, "Hydration properties of Portland cement-copper tailing powder composite binder," 
Construction and Building Materials, vol. 251, pp. 1178-1182, 2020.

[24] S. Liu, L. Wang, and B. Yu, "Effect of modified phosphogypsum on the hydration properties of the phosphogypsumbased supersulfated cement," Construction and Building Materials, vol. 214, pp. 9-16, 2019.

[25] R. Yuan, Cementitious Materials, Wuhan University of Technology Press, Wuhan, China, 1996.

[26] J. J. Thomas, J. J. Chen, H. M. Jennings, and D. A. Neumann, " $\mathrm{Ca}-\mathrm{OH}$ bonding in the $\mathrm{C}-\mathrm{S}-\mathrm{H}$ gel phase of tricalcium silicate and white Portland cement pastes measured by inelastic neutron s," Chemistry of Materials, vol. 15, no. 20, pp. 3813-3817, 2003.

[27] S. Liu, J. Ouyang, and J. Ren, "Mechanism of calcination modification of phosphogypsum and its effect on the hydration properties of phosphogypsum-based supersulfated cement," Construction and Building Materials, vol. 243, pp. 118-226, 2020.

[28] S. Liu, P. Fang, J. Ren, and Shefeng Li, "Application of lime neutralised phosphogypsum in supersulfated cement," Journal of Cleaner Production, vol. 272, pp. 1226-1260, 2020.

[29] P. K. Mehta and P. J. M. Monteiro, Concrete: Microstructure, Properties, and Materials, McGraw-Hill, London, UK, 2006. 